\title{
Problems and benefits of using a computer for laboratory data processing
}

\author{
F. V. FLYNN \\ From the Department of Clinical Pathology, University College Hospital, London
}

More experience in the routine use of computers probably exists in the field of pathology than in any other branch of medicine. Even so, the planning and setting up of a computer system for handling laboratory data presents many difficulties. Definitive answers to many of the problems which arise cannot be expected until a lot more experience has been built up and it will probably be some years before the ideal system emerges and is perfected. However, the undoubted benefits of using a computer make it worth while struggling to overcome the initial difficulties.

The problems and benefits discussed here are those which have been experienced at University College Hospital, London, when using an off-line computer to process biochemical data, and when planning for an on-line system which is to embrace all the data-handling activities of the chemical pathology service. Almost without exception, however, the problems and benefits are likely to be the same in all branches of pathology; many are discussed in greater technical detail elsewhere (Flynn, Alexander, Chalmers, Grant, Jenkins, Lapage, Robertson Smith, Squire, Stirland, Whitby, Whitehead, and Wootton, 1968).

\section{THE PROBLEMS}

SPECIFYING THE FUNCTIONAL REQUIREMENTS OF THE COMPUTER SYSTEM The expert designing a computer system needs to know very precisely what the machine will be expected to do, but most pathologists, like other specialists, are unlikely to be good at communicating their requirements to an outsider with no knowledge of their needs. During the detailed and logical examination of all the constituent processes of the data-handling system, problems are certain to arise from the jargon barrier, and from the staff either omitting to mention the familiar steps which are normally carried out without thinking or failing to recall all the exceptions to the general rules. Fortunately construction of a flow chart facilitates communication between the pathologist and the systems analyst and will be found extremely helpful for reviewing procedure and pinpointing unnecessary steps and bottlenecks.

Difficulties are also likely to arise when the systems analyst requests quantitative information about the data to be handled by the computer system. He will want to know, for instance, the average load of requests each day, the maximum number expected in any one day, the variation in load at different times of the day, and the number of urgent tests to be expected. He will also want to know such things as the number and length of individual reports, the average length of patients' records, the greatest length to be anticipated for any particular record, and the duration for which patients' records need to be kept in the active file. Some of these questions are readily answered but others involve a considerable amount of research (Fig. 1).

The systems analyst will also require an estimate of future needs, as there is no point in designing a system which is only adequate for present loads. It would seem sense to make provision for five to seven years ahead but the question is how to do this. A reasonably accurate prediction can usually be made by plotting on a logarithmic scale the request and test loads for several preceding years and extrapolating the lines forward (Fig. 2).

DECIDING WHAT COMPUTER FACILITIES SHOULD BE USED There are three main possibilities: the laboratory could have exclusive use of a small computer sited within its precincts, it could share the facilities of a hospital computer, or it could make use of a computer situated remotely from the hospital. In each case there would be a choice of on-line or off-line working but extensive use in the on-line mode would probably be practical only in the case of the laboratory computer. At the present time there is insufficient experience available to say which approach will prove best, but in practice the decision will be governed by what computer facilities are already available or planned. 


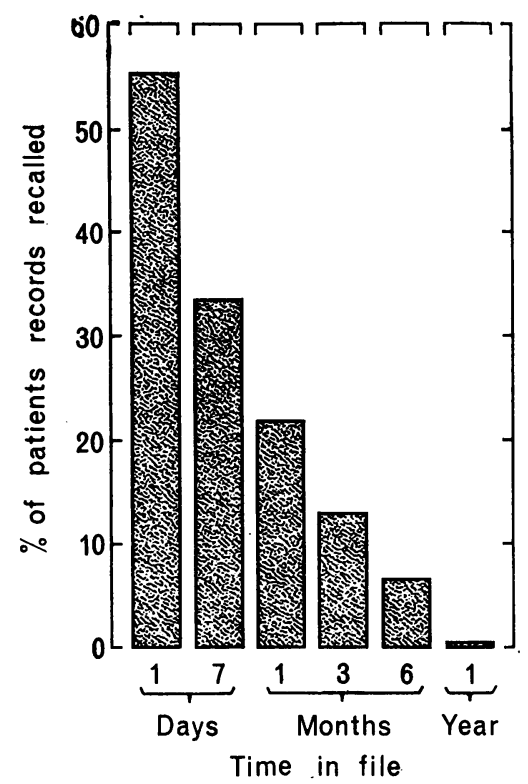

FIG. 1. An analysis of 8,652 patient records accumulated during a year on a file of chemical pathology results, showing the percentage of records that are recalled after varying intervals of time. Half the records examined had been held in store for at least eight months at the time of analysis.

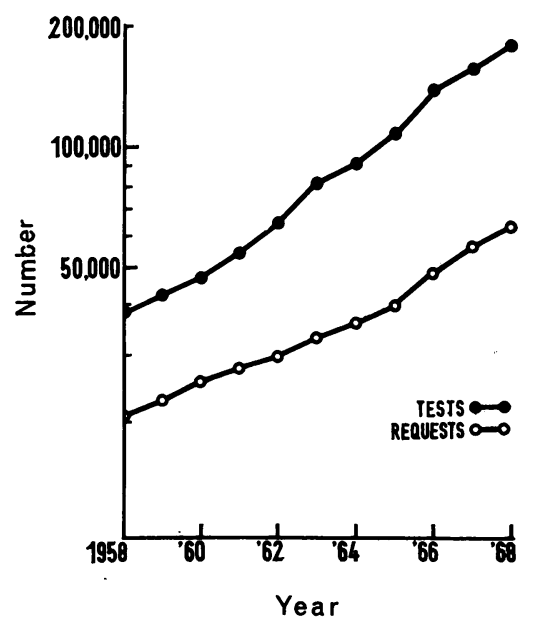

FIG. 2. A logarithmic plot of the request and test load in chemical pathology at University College Hospital over the years 1958-1968, showing how the growth in work load follows a predictable course.
In any event comprehensive laboratory data processing systems should not be planned in isolation as they must be compatible with medical record systems as a whole.

It seems possible that all laboratory records will eventually be stored in the files of central computer installations which will provide rapid access to all those who need the information. Therefore, when it is envisaged that a small laboratory computer will be used, it should be regarded as eventually forming a satellite to a bigger machine.

SELECTING HARDWARE Considerable difficulty arises when choosing equipment as there are many alternatives available and technological advances are so rapid that what seems the best today may be obsolete tomorrow. At the present time, too, when there is so little practical experience available to call upon, it is very difficult to get sound advice. The choice should be influenced by factors other than just price and technological excellence; the viability of the firm, its experience and reputation in the field, the software offered, the adequacy of service facilities, compatibility with existing equipment and with that of other manufacturers, and delivery dates should also be taken into account. Requirements for special accommodation should be allowed for when comparing items of hardware; apparatus needing special environmental conditions, with freedom from dust and close control of temperature and humidity, will necessitate a separate computer room with a costly air conditioning installation and additional communication links with the laboratory.

COLLECTING DATA FOR INPUT Several problems arise during the collection of data for computer input, the first being that of ensuring accuracy. Transcription should be avoided whenever possible and maximum use made of mechanical means of reproducing data. Handwritten entries should also be cut to a minimum, for example, by using request forms which have the test and specimen headings already printed so that all the clinician has to do is to put a mark against those that are appropriate.

A second problem is that of ensuring that the necessary data are complete. One way of achieving this is to transfer information in a block, for example, by reproducing patient identification data with an Addressograph plate. Another way is to design a special data-collection document which makes it obvious to the user when a particular item of information has not been entered (Fig. 3).

A third difficulty is that of ensuring that the information provided is adequate for its purpose and here patient identification is the chief 
DETERMINATION OF PIGMENTS IN LIQUOR AMNII

COMPUTER DATA SHEET

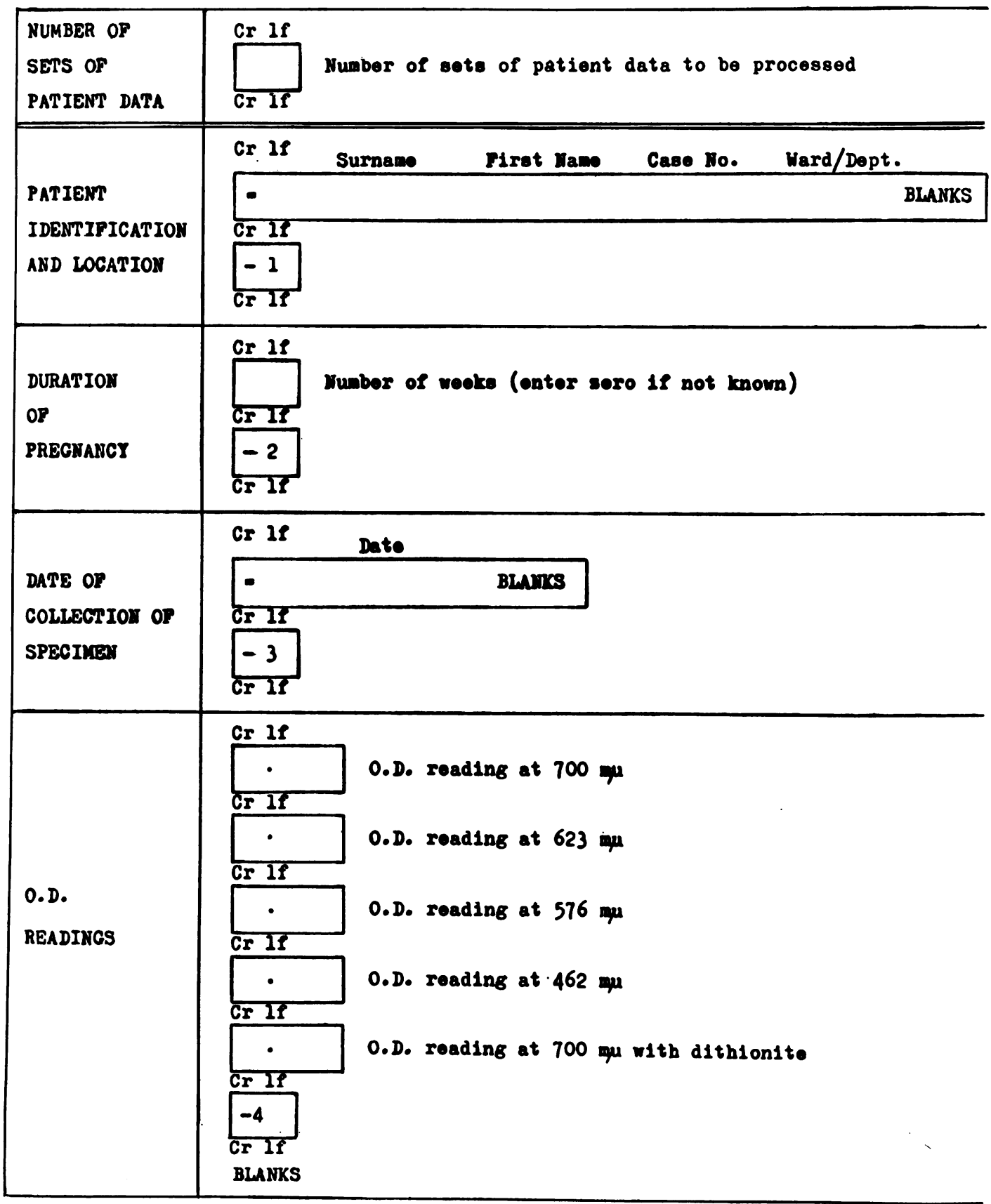

FIG. 3. An example of a document designed for collecting data for computer input via paper tape. 
problem. For the purpose of linking records on a patient, unique identification data are vital; quoting 'John Smith' may be adequate for the purpose of identifying a particular individual in a ward but it is totally inadequate for the purpose of updating that patient's laboratory record. The minimum requirement for identifying a patient at laboratory level is a unique personal number together with the surname. Wherever possible there should be additional data which will aid normal communication and provide a means of carrying out a check in the event of discrepancies, ie, full forenames, date of birth, sex and marital status, maiden name, location, and the requesting doctor's initials (Flynn et al, 1968). So essential is reliable patient identification that it is questionable whether it is possible to use a computer for full-scale laboratory data processing without at least an Addressograph system of reproducing the information. Even then it is difficult to get clinicians to use the system consistently, as house officers, for instance, like to write out request forms in their own rooms. Ideally, laboratory request cards bearing patient identification data in both conventional and machinereadable characters should be prepared at the time of registration and held in the patient's folder until needed (Whitehead, Becker, and Peters, 1968).

GETTING DATA INTO A FORM SUITABLE FOR MACHINE HANDLING To reduce the volume of data that has to be translated into machine-understandable binary language, it is frequently necessary to code the information first. In selecting suitable codes one has to reconcile the conflicting preferences of man and machine. The laboratory ideal is probably a simple mnemonic system which, if not already in use, can very readily be learnt. The computer programmer, on the other hand, would probably opt for digital codes but these necessitate the use of code books by the laboratory personnel. Two requirements that must not be overlooked when settling the coding problem are expansion capability for the future and avoidance of any code overlap.

A variety of techniques are available which enable data to be converted into machine-readable form but at the present time laboratory computer systems invariably make some use of keyboard equipment, which punches holes in paper tape or cards and at the same time prints the corresponding characters on a sheet of paper or the punched card. Further problems arise from this operation. First, the whole system tends to become dependent on the clerical staff who perform the task and it is very important therefore to make sure that there is more than one person capable of doing this particular job. Secondly, there is the risk of human error entering at this point, which necessitates some verification procedure; visual proof reading should pick up most of the errors but if they are to be eliminated entirely the information should be repunched by a second operator using a verifier. Errors of format can be avoided by the use of equipment which permits the layout to be programmed. Thirdly, keypunching may seriously hold up other work; the delay incurred in punching request information, for instance, could mean that it is not practical to produce technicians' work lists by computer because they would not become available early enough in the day. Fourthly, keypunching introduces a noise problem and steps will certainly have to be taken to dampen the sound of the punch.

Automatic data acquisition eliminates some of the problems of keypunching operations but only certain portions of laboratory data can be entered into a computer system in this manner. Equipment for capturing information directly in machinereadable form has mainly been developed for use with automatic analysis equipment and in particular with the AutoAnalyzer, and methods of automatically entering peak heights (Flynn, 1965, Flynn, Piper, and Roberts, 1966) and specimen identity (Rappoport, Gennaro, and Constandse, 1967) have now had extensive trials. Automatic data acquisition, while avoiding the limitations of manual keypunching, brings troubles of its own. The interface equipment itself may introduce errors; thus Edwards (1968) has shown how an imperfect slave slide wire used to interface the AutoAnalyzer to a computer caused an abnormal step-wise frequency distribution of patient results. Another problem with automatic data acquisition is how the data so entered are to be recognized as being valid. The Elliott A.L.A. off-line data-logging equipment that we have used at University College Hospital for several years to capture significant data from AutoAnalyzers copes well with most operating problems such as background noise on the recordings, swamping of low peaks by preceding high ones, and temporary absence of peaks. However, from time to time chemical irregularities cause the equipment to punch extra or incorrect peak values, which if not corrected when the data have been transferred into the computer store would cause serious errors in the results (Figs. 4 and 5). Ideally, automatic acquisition of data should include validation of all the data, but the real difficulty is how to imitate the assessment of peaks that is achieved by eye. Adequate differentiation of valid and invalid peaks has been achieved by Blaivas (1966) by providing an on-line computer 


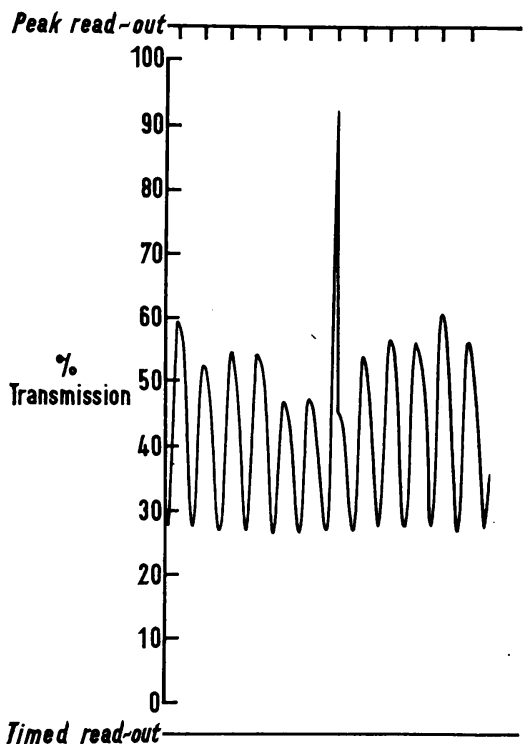

FIG. 4. An AutoAnalyzer recorder tracing showing an invalid peak caused by some chemical irregularity in the analytical system. Such a peak would trigger an incorrect reading to be taken by off-line automatic data acquisition equipment.

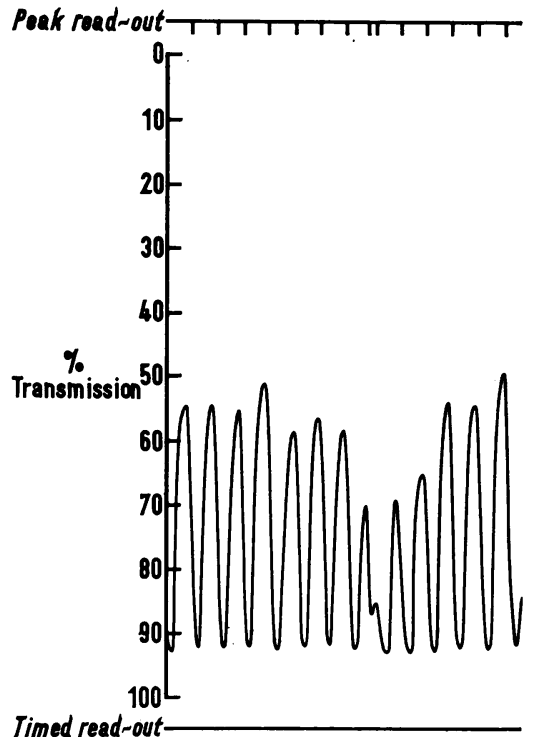

FIG. 5. An AutoAnalyzer recorder tracing showing a bifid peak caused by a very brief blockage of the sampling line by particulate matter in a specimen. Such a peak may cause an extra reading to be taken by off-line automatic data acquisition equipment. with a large amount of information describing the total shape of the curve and then testing the data to see if a number of criteria are satisfied. This approach needs a considerable amount of programming effort and permanently locks up a sizeable portion of the computer's core store.

There is a halfway house between manual keypunching and automatic data acquisition for entry of AutoAnalyzer data. This is represented by ${ }^{2}$ equipment such as the d-Mac pencil follower and the $\vec{O}$ Normalair Garrett trace reader. Such equipment enables laboratory staff to record peak heights ${ }_{\sigma}^{\omega}$ sequentially on punched paper tape merely by operating a switch when a cross-wire or stylus is i centered over the zenith of each peak. With practice the process can become extremely rapid; using a d-Mac pencil follower at University College Hospital we have found that it is possible to convert 1,000 peaks into binary code within half an hour. Human error may creep in once more but the visual vetting of peaks is worth a lot of computing time and programming effort.

WRITING COMPUTER PROGRAMS Several difficulties $\vec{\varphi}$ confront one when computer programs are to be written, the first being that of recruiting programming staff. Such people are in very short supply, especially those with hospital experience. If one takes on a newcomer or elects to train someone within the hospital, it takes a year or so before he is able to programme with any degree of efficiency.

Difficulties are also likely to arise when specifying precisely what is to be done by the program. Decisions have to be taken on such things as the criteria which must be fulfilled before a set of calibration standards are to be regarded as satisfac- $\frac{c}{0}$ tory. This particular question may prove fairly $:$ easy to answer because it is a familiar one but the difficulty of defining what comprises an accept- 8 able AutoAnalyzer peak can be readily imagined.

The choice of programming language creates $ᄋ$ another dilemma. The advantage of a problem- $D$ orientated high level language, in which one can write programs much more rapidly, may have to be sacrificed if only a small computer is available. O The reason for this is that the same program written $\tilde{N}$ in a machine-orientated language uses up less of the $\underset{\omega}{\mathscr{\omega}}$ core store and executes the job in a shorter time. F However, as far as possible one should strive to 0 avoid the machine-orientated languages because the $\stackrel{\mathbb{D}}{\overparen{D}}$ programs written in them will be machine specific. $\stackrel{?}{+}$

The final problem arising during programming 0 is the length of time taken to deliver the perfect article. The period allowed for the trial and correction of the program is often underestimated. Another $\stackrel{D}{\triangle}$ cause of delay is staff turnover; programmers are $\bar{Q}$ 
very liable to move in order to widen their experience and grave difficulties are liable to be encountered at the time of handing over unless very good documentation has been achieved. Alterations to the specification of a program can also cause serious delays and should be avoided as far as is possible by giving adequate thought to the problems beforehand.

GETTING DATA OUT OF THE COMPUTER The first problem here is that of output speed. This is liable to be far too slow with a teleprinter, operating at 10 to 14 characters per second, and yet in many cases the volume of output is not great enough to justify the use of a fast line-printer unless it is being shared with other users. The dilemma seems likely to be solved by equipment of intermediate price which has recently appeared on the market; this operates at speeds between 40 and 140 characters per second.

A second problem is that of timing. When an off-line computer is used in a batch-processing mode, laboratory results may only become available late in the day; if errors are revealed at this point in time it may not be possible to deal with them the same day (Whitby, Proffitt, and McMaster, 1968). This particular problem should not arise with an on-line computer which is able to detect and report errors as they occur and produce reports at frequent intervals.

Another problem concerns the dimensions of stationery which are acceptable to standard output devices. These are at variance with the international paper sizes recommended for use in the National Health Service; thus, unless trimmed, computerproduced reports are incompatible in size with all the other documents forming the patient's case notes.

One further problem is the noise created by output devices. This is considerable and is less tolerable than that from input devices as it proceeds in a continuous and monotonous fashion. It is essential, therefore, to soundproof the area where such equipment is placed.

COMMISSIONING THE COMPUTER SYSTEM Persuading staff to accept change is always a problem, especially when they have been in the department for some years. Much patience and tact are needed because of the prevalance of emotional attitudes towards computers and because the staff are being asked to operate what is inevitably a more rigid system. It is not only the laboratory staff who have to be won over if the new system is to work smoothly; some time may have to be spent in explaining the new requirements of the laboratory to the clinicians, the nurses, and medical records staff. An educational programme for those directly involved in operating the system should begin some months before implementation.

Another problem is the amount of extra work to be faced while the new system is being tested and adjusted. Faults in programs may continue to be discovered over a period of months as unusual combinations of circumstances may be needed to bring them to light. A prolonged period of parallel running of the new and old systems must therefore be expected and an attempt should be made to obtain additional clerical help for this stage.

OPERATING THE COMPUTER SYSTEM When a laboratory has to share an off-line computer with others, adherence to a strict time schedule will often pose a major problem. Transport delays, fluctuations in work load, technical problems, and urgent specimens all make it extremely difficult to keep to a hard and fast timetable, so some flexibility of computer bookings should be negotiated if at all possible. The alternative is very rigid organization within the laboratory, but with so many uncontrollable factors and a constantly changing staff this never seems to work in practice.

Malfunction of equipment can produce errors which are very difficult to trace, especially when faults are intermittent. This problem arises particularly with peripheral equipment having moving parts, such as card or paper tape readers and punches, and magnetic tape handlers. The routine running of a test program at the start of each day, to check the performance of all the components, is probably worthwhile but it does not guarantee freedom from troubles later. Investment in good environmental control, especially control of dust, is an important prophylactic against malfunction of magnetic storage devices, and when a built-in check on parity is offered as an optional extra on an item of off-line hardware it should always be taken up. To lessen the chance of faulty peripherals corrupting the data being entered into the computer, checks on such things as the number of characters and the presence of specific markers should be included in the program input routine whenever possible.

Complete breakdown of equipment is inevitable sooner or later and it is vital therefore to have a full backing-up procedure worked out in advance. The effects of breakdown could be catastrophic in real-time computing and in this situation it is probably justifiable to duplicate certain key components of the system. Routine maintenance is usually advocated but a really satisfactory contract to deal with breakdowns is more important; what is required is an unequivocal assurance that breakdowns will be dealt with swiftly and that only highly trained 
and experienced engineers will be sent to carry out the repairs. The items of equipment which seem to be particularly prone to breakdown are the airconditioning plant, teleprinters, and magnetic backing stores. Operational breakdowns may also arise from power failures, and as far as possible one should ensure that the power supply is isolated from the effects of surges on heavy duty circuits and that it is not likely to be interrupted by an electrician pulling out all the fuses when dealing with a fault somewhere else in the building. It seems impracticable to provide backup for a mains power failure because of the expense involved.

The updating of programs is another operational problem. Laboratory procedure does not stand still and it is essential that the software can be altered as occasion demands. This is likely to prove very difficult unless one can retain the services of the programmer who wrote the original version, or unless the documentation of the programs is so good that it permits anyone else to delve into them with ease at a later date.

The final problem arising when running a computer data processing system concerns the training of staff. Those working in highly automated, computerized laboratories get little or no practice at calculation and this puts them at a disadvantage when they come to sit their qualifying examinations. One can but hope that those responsible for the examinations will take cognisance of this.

JUSTIFYING THE COST Computerization of laboratory procedure requires a considerable capital investment. The small laboratory computer may well cost between $£ 20,000$ and $£ 50,000$ by the time all the peripheral equipment and the software are added, and the question that inevitably arises is whether or not this money is being wisely spent. The Department of Health and Social Security are financing various experimental systems in order to assess the value of the laboratory computer, but the findings are unlikely to be forthcoming before 1971 .

\section{THE BENEFITS}

REEXAMINATION OF EXISTING PROCEDURE Having to look again at the existing data processing system is undoubtedly a benefit. Very often present procedure is a legacy of the past and it is a salutary exercise to have to justify it to an outsider like a systems analyst. The economic constraints of a computer system are such that one must be certain that each constituent operation really serves a useful function.

REDUCTION IN CLERICAL WORK FOR TECHNICAL AND SCIENTIFIC STAFF Existing methods of data pro- cessing are wasteful of the time of skilled personnel; $\stackrel{\stackrel{\underline{\partial}}{\Rightarrow}}{\Rightarrow}$ in highly mechanized biochemical laboratories it has $\stackrel{0}{\rightarrow}$ been estimated that technicians spend about $30 \%$ 음 of their time on clerical work (Rappoport, 1965). With an on-line computer system it should be $\frac{\text { s }}{\square}$ possible to eliminate this type of work almost $\stackrel{\mathbb{D}}{\stackrel{2}{ }}$ entirely. With an off-line system it has been possible ${ }^{\circ}$ to reduce the paper work for the non-clerical staff $\vec{\circ}$ considerably; for some tests at University College Hospital there is no writing other than the recording $\vec{\omega}$ of which specimen is put into a particular AutoAnalyzer cup and no calculation of urine outputs? or clearances. Elimination of this paper work is in currently saving about 31 man hours each week.

REDUCTION IN THE NUMBER OF ERRORS There are several reasons for expecting the frequency and $\frac{}{5}$ magnitude of errors to be reduced. In the case of the AutoAnalyzer with automatic data acquisition it is possible to carry out checks on the analytical performance quite automatically. By programming $\stackrel{\rho}{2}$ the computer to establish that the calibration $\vec{\bullet}$ standards fall within defined limits, reagents, standards, the performance of the apparatus, and the order of loading are all validated. The standard of work is raised as a result because the checking procedure is consistently applied and cannot be circumvented. Automatic validation of the individual peaks registered by AutoAnalyzers can eliminate other sources of error. With the Elliott ALA off-line data acquisition equipment, peaks affected by serious carryover are automatically marked for repeat, and with an on-line computer system other types of invalid peaks, such as those due to a short sample, could be consistently detected and immediately scheduled for repeat analysis.

Errors due to inaccurate reading of the AutoAnalyzer tracing can also be eliminated. Peak heights can be read more accurately by automatic data acquisition equipment than is possible by eye but more important is the elimination of misreadings. The latter are liable to occur when the values of peaks are read off manually because the figures at $\mathscr{O}$ the top of the reading chart are far removed from the point of intersection being noted.

Errors of calculation can also be eliminated. At University College Hospital we have investigated 0 retrospectively the frequency of errors of calculation $\stackrel{\overparen{D}}{\overparen{D}}$ when using an optical density ratio method to $\stackrel{9}{?}$ determine the concentration of pigments in specimens of liquor amnii. Computer-calculated results were compared with those produced manually under ordinary working conditions. Only addition, subtraction, and multiplication are involved but altogether there are 13 arithmetical operations and a sizeable error can result from a slip at an early 
TABLE I

FREQUENCY OF READING AND RECORDING ERRORS WHEN READING AUTOANALYZER PEAKS MANUALLY UNDER ROUTINE CONDITIONS ${ }^{1}$

\begin{tabular}{|c|c|c|c|c|}
\hline \multirow[t]{2}{*}{ Determination } & \multirow[t]{2}{*}{ Number of Results } & \multicolumn{3}{|l|}{ Error } \\
\hline & & Magnitude & Frequency (\%) & Type \\
\hline Urea $(\mathrm{mg} / 100 \mathrm{ml})$ & 1,001 & $\begin{array}{l}1 \\
2-3 \\
4-6 \\
7-12\end{array}$ & $\begin{array}{r}39 \cdot 7 \\
18 \cdot 9 \\
1 \cdot 7 \\
2 \cdot 0\end{array}$ & $\begin{array}{l}\int_{\text {Transcription }} \text { Reading reading } \\
\text { Res }\end{array}$ \\
\hline Bicarbonate (m-equiv/l) & 1,039 & $\begin{array}{l}1 \\
2 \\
4-6 \\
9-11\end{array}$ & $\begin{array}{r}26 \cdot 1 \\
0 \cdot 3 \\
0 \cdot 2 \\
0 \cdot 2\end{array}$ & \}$_{\text {Transcription } \pm \text { reading }}$ Reading \\
\hline Chloride (m-equiv/l) & 1,010 & $\begin{array}{l}1 \\
2-3 \\
4-5 \\
10-12\end{array}$ & $\begin{array}{r}36 \cdot 7 \\
6 \cdot 9 \\
0 \cdot 5 \\
0 \cdot 2\end{array}$ & \}$_{\text {Transcription } \pm \text { reading }}$ Reading \\
\hline Sodium (m-equiv/l) & 1,010 & $\begin{array}{l}1 \\
2 \\
3\end{array}$ & $\begin{array}{r}41 \cdot 2 \\
2 \cdot 3 \\
0 \cdot 1\end{array}$ & \} Reading \\
\hline Potassium (m-equiv/1) & 1,026 & $\begin{array}{l}0 \cdot 1 \\
0 \cdot 2 \\
0 \cdot 3-0 \cdot 4 \\
1 \cdot 0-1 \cdot 1\end{array}$ & $\begin{array}{r}31 \cdot 9 \\
2 \cdot 2 \\
0 \cdot 2 \\
0 \cdot 2\end{array}$ & \}$_{\text {Transcription } \pm \text { reading }}$ Reading \\
\hline
\end{tabular}

${ }^{1}$ The correct results were produced by computer without human intervention.

stage. Because of this we designed a special work sheet for performing the calculation, with spaces for the insertion of figures and instructions as to what to do at the different stages. Even using this form, and insisting that in every case the calculation was checked by a second person, we found that six out of $\mathbf{8 1 ~ h a d ~ a ~ s i z e a b l e ~ e r r o r . ~ I n ~ f o u r ~ c a s e s ~ t h e ~ e r r o r ~}$ was not of clinical significance but in two cases it was serious in that it might have led to the obstetrician terminating the pregnancy earlier or later than was necessary.

Computer systems also stand to eliminate those errors of transcription which inevitably occur under ordinary working conditions as a result of distractions and interruptions. Errors of transcription are particularly liable to occur during the reading of AutoAnalyzer charts when one technician is writing down what has been read by another; 35 gets misheard and written down as 25 , and so on. When we compared the results produced from 5,086 AutoAnalyzer peaks by a computer system with those produced by the laboratory staff under routine conditions (Table I), we found 53 significant errors in the manual results, only some of which were subsequently detected by routine checking procedures. Twenty-seven of these errors were considered to be due to inaccurate reading of the peak height or inaccurate correction for drift, and 26 due to a transcription error. Interestingly, when this latter type of error occurred the figure recorded was very frequently biased towards normality.
With a computer system it is possible automatically to flag those results which should be scrutinized carefully by the pathologist. This should improve the efficiency of the final check and therefore contribute another means of reducing the error rate. In the computer program devised at University College Hospital for processing the data from the electrolyte AutoAnalyzer, a cross-check between the plasma results is performed by calculating the anion-cation difference; in the printed table of results produced for the laboratory an asterisk is placed against results with an ion difference greater than 20 or less than 12 m-equiv/l (Fig. 6).

FASTER PRODUCTION OF RESUlTS Even with a relatively slow computer, such as the Elliott 803 machine, the time taken to perform calculations can be appreciably reduced. The actual operating time required on the 803 to produce and interpret the results of a calculation of the concentration of pigments in a specimen of liquor amnii is 13 seconds compared with 10 to 15 minutes by hand. To this operating time, however, should be added the one or two minutes taken to punch the data tape, the 30 seconds taken to load the necessary program into the computer, and the two minutes required by an off-line teleprinter to print the results from the output tape. With more complex calculations and data handling procedures the benefits in this direction become more impressive. At University College Hospital, using the Elliott 803 computer and a tele- 


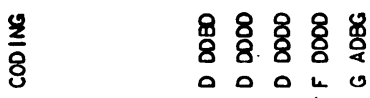
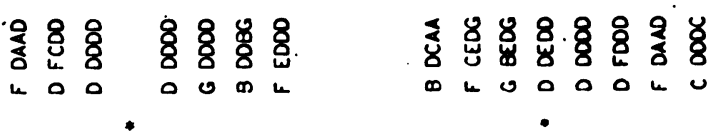

$\because \sim 3 \stackrel{*}{\circ}$

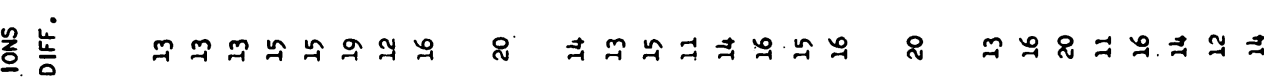

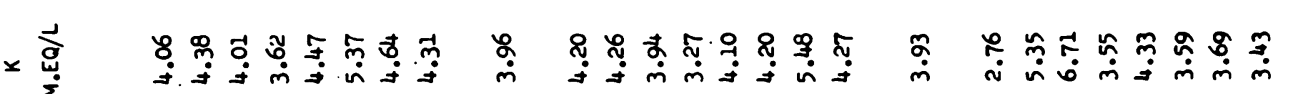

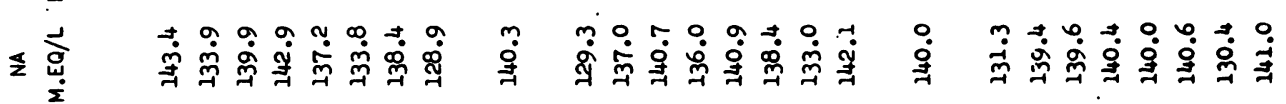

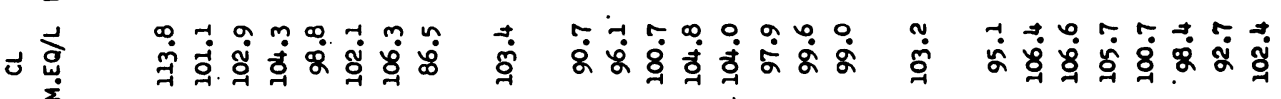

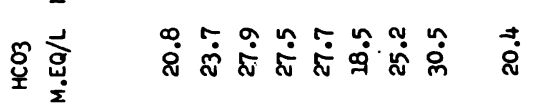

웅

\&

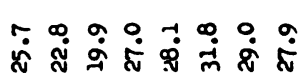

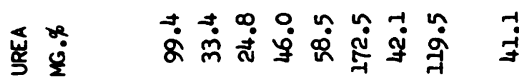

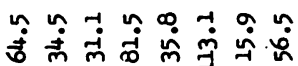

$\stackrel{\circ}{\circ}$

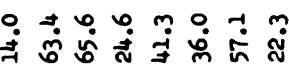

원 웅

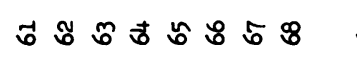

ส

o

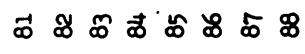

$\underset{\underline{\underline{w}}}{\underline{\underline{w}}}$

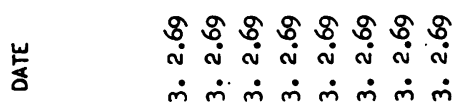

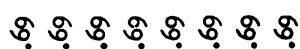

ن

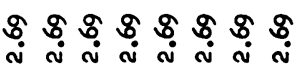

$\dot{m} \dot{m} \dot{m} \dot{m} \dot{m} \dot{m} \dot{m}$

$\ddot{m} \dot{-1} \dot{\sim} \dot{m} \dot{m} \dot{m} \dot{m}$

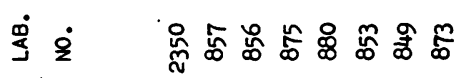

๖品

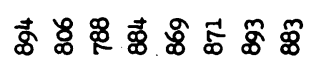

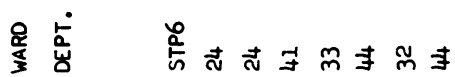

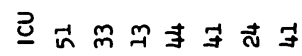

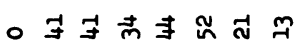

品

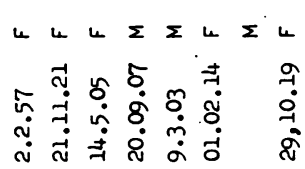

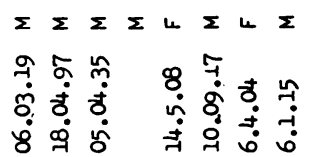

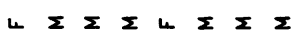

$\stackrel{\leftrightarrow}{\dot{0}}$

$\dot{q}$

岁

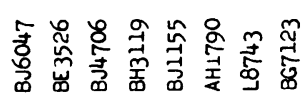

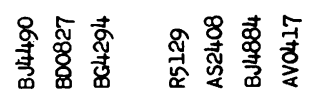

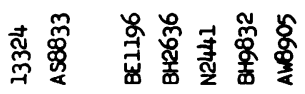

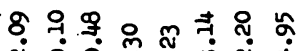
สำ จุำ त

$\frac{w}{2}$

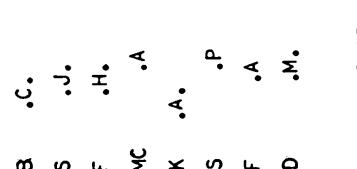

$$
\text { 葆 }
$$

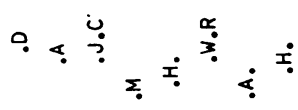$$
\text { 容 }
$$

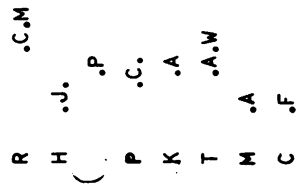

डิ के to

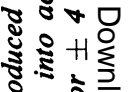

춘웡

密

\& : 응

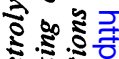

ชิำ

ริํํำํํำ

范

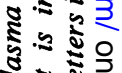

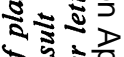

จ

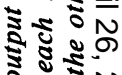

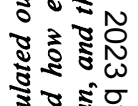

ริ ริำ

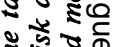

จุำ

고 중

6 施

क्षें 
EXAMIINATION OF LIQUOR AMNII automatically add an indication of the normality or otherwise of a given result, taking into account such factors as sex and age (Fig. 6). Doing this without a computer is quite impracticable because

G--N JEAN AJ6035 OH OND

DURATION OF PREGMNCY = 32 WEEKS

DATE OF COLLECTION OF SPECIMEN $=11 \cdot 7.67$

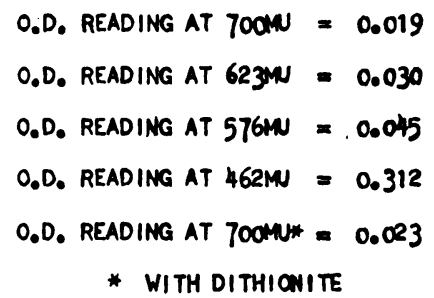

\begin{tabular}{|c|c|c|c|}
\hline METHAEMALBUMIN & & 0.05 & MG/100ML \\
\hline OXYHAEMOGLOBIN & & 1.37 & MG/100M \\
\hline BILIRLBIA & & 0.32 & MG/100ML \\
\hline
\end{tabular}

HAEMOLYTIC DISEASE WILL BE SEVERE

AND DELIVERY SHOULD BE EFFECTED BY THE 36TH WEEK

FIG. 7. Output produced by a computer program which is used to calculate pigment concentrations in specimens of liquor amnii. The interpretation of the result takes the duration of pregnancy into account and suggests the clinical action which should follow.

printer operating at 10 characters/second, the total time taken to produce 104 sets of urea and electrolyte results from a data tape bearing peak height information on 750 AutoAnalyzer peaks can be as little as 25 minutes, including eight minutes' computer time. The same output produced entirely by hand would take many hours to appear because it includes a calculation of standard deviations; without the latter it would require just over one-and-a-half man hours if two technicians worked on the job.

Faster results are not necessarily synonymous with speedier reporting. The benefits of faster manipulation of data tend to be nullified by the use of a computer in a batch-processing mode, especially when it is devoid of a fast output device such as a line printer. The time lost while the data are held in the queue awaiting computer processing may not be offset by the subsequent saving of time.

IMPROVED INTERPRETATION OF RESULTS It is possible to include routines in a computer program which it is impossible either to carry the multitude of normal ranges in one's head or to find time to look them up in an appropriate table. In the program we have developed for the calculation of pigment concentrations in specimens of liquor amnii, we have gone one step further in getting the computer to suggest the clinical action which should follow the finding of a particular result (Fig. 7). This saves having to look up or memorize the correct interpretation of a test which is not very frequently carried out.

IMPROVED PRESENTATION OF RESULTS With a computer system, typewritten reports of consistent format can be automatically produced for the clinicians and for the laboratory. Computer systems making use of the backing stores for retention of previous results are compatible with the practice of cumulative reporting, which lessens the bulk of reports filed in the case notes and provides the clinician with a well organized summary of all the patient's laboratory results in date sequence (Flynn and Vernon, 1965; Whitby and Owen, 1965).

FASTER COMMUNICATION OF RESUlts At present a large proportion of the time taken to return a result to the clinician is taken up in transmitting the report from the laboratory to the periphery. Faster transmission could be achieved with a computer system by making use of a teleprinter link, and the saving in time could be very significant, especially where laboratory services are centralized. The laboratory stands to benefit from such a procedure in so far that it should lessen the enquiries which disrupt its clerical services.

IMPROVED QUALITY CONTROL With a computer available it becomes practical to employ a statistical approach to quality control, using the mean value of near-normal patient results to assess the performance of a method (Whitehead, 1965; Whitby, Mitchell, and Moss, 1967). At University College Hospital we have found that this technique provides an earlier warning of a method getting out of control than any other procedure and we have now built it into all the computer programs used for dealing with the processing of AutoAnalyzer results (Flynn, 1966). An important advantage of having such information produced automatically is that it is available when the results are being scrutinized and not retrospectively. An example of a quality 


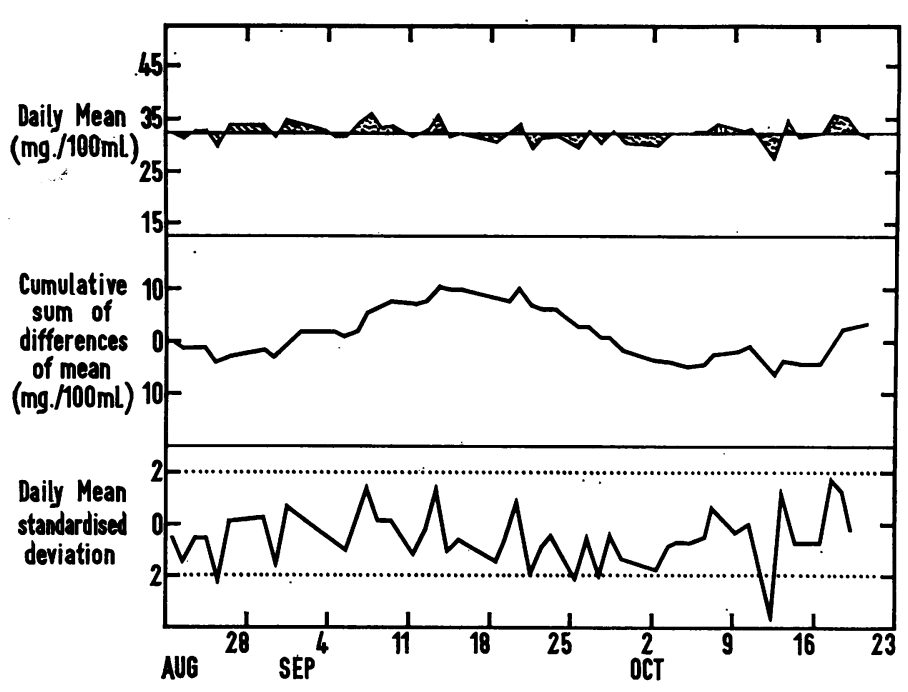

FIG. 8. A quality control chart drawn up from data returned by the computer when processing information from an AutoAnalyzer measuring urea. Daily means of all plasma results between 15 and $50 \mathrm{mg} / 100 \mathrm{ml}$ are plotted, also the cumulative sum of the difference between the daily means and the figure taken as the average value. When the value for the daily mean standardized deviation exceeds 3 , action to get the method under control is required and when it is greater than 2 but less than 3 the staff should be alerted to look for trouble. control chart drawn up from data returned by the computer is shown in Figure 8.

MORE COMPACT STORAGE OF RESULTS The storage of laboratory records in a very compact form could be another important advantage of computer systems. At University College Hospital we have calculated that when all the chemical pathology records are stored on a magnetic tape file it should be possible to hold a year's results on one reel of tape 12 in. in diameter and $\frac{1}{2}$ in. thick. The same number of results held on cumulative record cards would require 12 cubic feet of filing space.

EASIER ANALYSIS OF RECORDS Because of the high speed of search and retrieval operations and the absence of misfiling it is possible to analyse records held on a computer file much more easily and reliably than is possible with manual procedures. The benefits in the realm of laboratory management could be considerable; for example, regular examination of the workload for changes in its pattern should lead to more rational planning of laboratory development and allocation of resources. The ease of specific and class retrieval of data and the possibility of performing linkage studies with other parts of the medical record also open up exciting possibilities for research.

\section{SUMMARY}

The problems and benefits of using a computer for laboratory data processing are discussed in the light of experience obtained at University College Hospital, London, in the last five years.

The problems covered include the specification of the functional requirements of the computer system, the choice of computer facilities and of hardware, the difficulties associated with getting data into and out of the computer, the writing of computer programs, the commissioning and operation of the system, and the justification of the costs.

The benefits discussed include the streamlining of existing procedure, the reduction in clerical work and in errors, the faster production and communication of results and their improved interpretation and presentation, better quality control, more compact storage of results, and the better accessibility of records for analysis.

I wish to acknowledge the contributions of $\mathrm{Mrs} \mathrm{H}$. Hawkins, Mr M. J. Healy, Mr K. A. Piper, and Miss G. Richards to some of the work reported here. I am also indebted to the Department of Health and Social Security for research grants that made this work possible and to Mr V. K. Asta for the diagrams.

\section{REFERENCES}

Blaivas, M. A. (1966). In Automation in Analytical Chemistry, edited by L. T. Skeggs, p. 452. Mediad, New York.

Edwards, R. G. (1968). Personal Communication.

Flynn, F. V. (1965). In Progress in Medical Computing (Symposium organized by Elliott Medical Automation, London 1965). p.46. Blackwell, Oxford.

- , and Vernon, J. (1965). J. clin. Path., 18, 678.

- (1966). Proc. roy. Soc. Med., 59, 779.

-

-, Alexander, M. K., Chalmers, D. G., Grant, G. H., Jenkins, W. J., Lapage, S. P., Robertson Smith, D., Squire, J. R., Stirland, R. M., Whitby, L. G., Whitehead, T.P., and Wootton, I. D. P. (1968). Ibid., 21, 231. 
Rappoport, A. E. (1965). In Symposium on Computer-assisted Pathology, College of American Pathologists, 1964, p. 4. Chicago.

Gennaro, W. D., and Constandse, W. J. (1967). Mod. Hosp., $108,107$.

Whitby, L. G., and Owen, J. A. (1965). J. clin. Path., 18, 668.

Mitchell, F. L., and Moss, D. W. (1967). Advanc. Clin. Chem. 10,65 .
Proffitt, J., and McMaster, R. S. (1968). Scot. med. J., 13, 181

Whitehead, T. P. (1965). In Progress in Medical Computing (Symposium organized by Elliott Medical Automation, London, 1965), p. 52. Blackwell, Oxford.

-, Becker, J. F., and Peters, M. (1968). In Computers in the Service of Medicine, edited by G. McLachlan and R. A. Shegog, Vol. 1, p. 113. Oxford University Press. 